\title{
Definitive chemoradiotherapy versus neoadjuvant chemoradiotherapy followed by surgery for stage II to III esophageal squamous cell carcinoma
}

\author{
Arianna Barbetta, MD, ${ }^{\mathrm{a}}$ Meier Hsu, MS, ${ }^{\mathrm{b}}$ Kay See Tan, PhD, ${ }^{\mathrm{b}}$ Dessislava Stefanova, MD, ${ }^{\mathrm{a}}$ \\ Koby Herman, MD, ${ }^{\mathrm{a}}$ Prasad S. Adusumilli, MD, ${ }^{\mathrm{a}}$ Manjit S. Bains, MD, ${ }^{\mathrm{a}}$ Matthew J. Bott, MD, ${ }^{\mathrm{a}}$ \\ James M. Isbell, MD, ${ }^{a}$ Yelena Y. Janjigian, MD,${ }^{c}$ Geoffrey Y. Ku, MD, ${ }^{c}$ Bernard J. Park, MD, ${ }^{a}$ \\ Abraham J. Wu, MD, ${ }^{d}$ David R. Jones, MD, and Daniela Molena, MD $^{a}$
}

\section{ABSTRACT}

Objective: Definitive chemoradiotherapy (CRT) remains the most commonly used treatment for locally advanced esophageal squamous cell carcinoma (SCC), because of perceptions that esophagectomy offers an unclear survival advantage. We compare recurrence, overall survival (OS), and disease-free survival (DFS) in patients treated with definitive CRT or neoadjuvant CRT followed by surgery (trimodality).

Methods: This was a retrospective cohort study of patients with stage II and III SCC of the middle and distal esophagus in patients who completed CRT. Treatment groups were matched $(1: 1)$ on covariates using a propensity score-matching approach. The effect of trimodality treatment, compared with definitive CRT, on OS, DFS, and site-specific recurrence was evaluated as a time-dependent variable and analyzed using Cox regression with a gamma frailty term for matched units.

Results: We included 232 patients treated between 2000 and 2016: 124 (53\%) with definitive CRT and 108 (47\%) with trimodality. Trimodality was used less frequently over time $(61 \%$ before 2009 and $29 \%$ after $2009 ; P<.0001)$. After matching, each group contained 56 patients. Median OS and DFS were 3.1 and 1.8 years for trimodality versus 2.3 and 1.0 years for CRT. Surgery was independently associated with improved OS (hazard ratio, $0.57 ; 95 \%$ confidence interval, 0.34-0.97; $P=.039$ ) and DFS (hazard ratio, $0.51 ; 95 \%$ confidence interval, 0.32-0.83; $P=.007)$.

Conclusions: CRT followed by surgery might decrease local recurrence and increase DFS and OS in patients with esophageal SCC. Until better tools to select patients with pathological complete response are available, surgery should remain an integral component of the treatment of locally advanced esophageal SCC. (J Thorac Cardiovasc Surg 2018;155:2710-21)

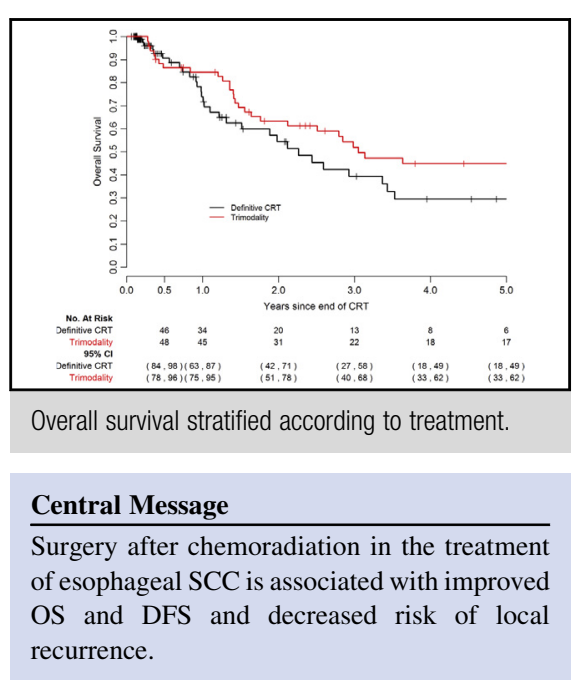

\section{Perspective}

Because patients with esophageal SCC have a high rate of $\mathrm{pCR}$ after chemoradiotherapy, surgery is often considered optional and reserved for patients with poor response. In this study, we show that CRT followed by surgery is associated with a lower risk of local recurrence and improved DFS and OS. Patients with esophageal SCC should be consulted about the potential advantages of surgical resection.

See Editorial Commentary page 2722.
After the enthusiastic results of the CROSS (Chemoradiotherapy for Oesophageal Cancer Followed by Surgery Study) trial, which proved the superiority of multimodality

From the ${ }^{\mathrm{a}}$ Thoracic Service, Department of Surgery, ${ }^{\mathrm{b}}$ Department of Epidemiology and Biostatistics, 'Gastrointestinal Oncology Service, Department of Medicine, and ${ }^{\mathrm{d}}$ Department of Radiation Oncology, Memorial Sloan Kettering Cancer Center, New York, NY.

This study was supported, in part, by National Institutes of Health/National Cancer Institute Cancer Center Support Grant P30 CA008748. A.B. is supported by a Surgeon Development award from the Esophageal Cancer Education Foundation. Read at the 97th Annual Meeting of The American Association for Thoracic Surgery, Boston, Massachusetts, April 29-May 3, 2017. therapy over surgery alone for esophageal cancer, ${ }^{1,2}$ neoadjuvant chemoradiotherapy (CRT) has become the standard of care for locally advanced disease in the

Received for publication June 1, 2017; revisions received Jan 4, 2018; accepted for publication Jan 31, 2018; available ahead of print March 13, 2018.

Address for reprints: Daniela Molena, MD, Thoracic Surgery Service, Department of Surgery, Memorial Sloan Kettering Cancer Center, 1275 York Ave, New York, NY 10065 (E-mail: molenad@mskcc.org). $0022-5223 / \$ 36.00$

Copyright (C) 2018 by The American Association for Thoracic Surgery https://doi.org/10.1016/j.jtcvs.2018.01.086 


\section{Abbreviations and Acronyms}

$\begin{array}{ll}\text { CI } & =\text { confidence interval } \\ \text { CROSS } & =\text { Chemoradiotherapy for Oesophageal } \\ & \text { Cancer Followed by Surgery Study } \\ \text { CRT } & =\text { chemoradiotherapy } \\ \text { cStage } & =\text { clinical stage } \\ \text { CT } & =\text { computed tomography } \\ \text { DFS } & =\text { disease-free survival } \\ \text { DR } & =\text { distant recurrence } \\ \text { HR } & =\text { hazard ratio } \\ \text { IQR } & =\text { interquartile range } \\ \text { JCOG } & =\text { Japan Clinical Oncology Group } \\ \text { LR } & =\text { local recurrence } \\ \text { NA } & =\text { not available } \\ \text { OS } & =\text { overall survival } \\ \text { pCR } & =\text { pathological complete response } \\ \text { PET } & =\text { positron emission tomography } \\ \text { RR } & =\text { regional recurrence } \\ \text { SCC } & =\text { squamous cell carcinoma } \\ \text { SMD } & =\text { standardized mean difference } \\ \text { SUV } & =\text { standardized uptake value } \\ \text { SUV } & =\text { maximum standardized uptake value } \\ \text { Trimodality } & =\text { neoadjuvant chemoradiotherapy } \\ & \text { followed by surgery }\end{array}$

(U) Scanning this QR code will
take you to a supplemental
video, figure, and tables. To
view the AATS Annual
Meeting Webcast, see the
URL next to the webcast
thumbnail.

United States. However, despite the recommendations of the National Comprehensive Cancer Network, ${ }^{3}$ the role of surgery after CRT as an indispensable component of curative therapy has been challenged in the past few years. In a recent analysis of the Surveillance, Epidemiology, and End Results-Medicare Linked Database, we found that only $5 \%$ of patients with locally advanced esophageal cancer received neoadjuvant therapy followed by surgery; most patients $(49 \%)$ were treated with definitive CRT. The most common reason for exclusion of surgery was that surgery was not recommended $(73 \%))^{4}$ This observed trend is likely attributable to several important misconceptions: (1) a nihilistic approach toward esophageal cancer in general, which is often considered a systemic disease at diagnosis without much hope for local therapy; (2) an unfavorable reputation of esophagectomy as a surgical procedure with high postoperative complication rates and impaired long-term quality of life; and (3) a perception that CRT leads to pathological complete response (pCR) in a high percentage of patients. The latter statement is particularly true for squamous cell carcinoma (SCC) of the esophagus, which is infrequently seen in the United States today but has been shown to have a higher sensitivity to CRT, with pCR rates up to $46 \%$ to $49 \%$. $^{1,5}$

Two major randomized trials compared definitive CRT with neoadjuvant CRT followed by surgery (trimodality) for esophageal SCC. Although surgery was associated with improved local control, both trials failed to show a survival benefit when surgery was used in addition to the treatment regimen. ${ }^{6,7}$ Conversely, several retrospective studies have reported improved survival outcomes with trimodality treatment, supporting the view that definitive CRT should be reserved for patients who are unsuitable for surgery. ${ }^{8-12}$ Although it seems reasonable to assume that patients with pCR would not benefit from surgical resection, there are no reliable tools to preoperatively identify these patients. We previously showed that, after completion of CRT, a reduction of positron emission tomography (PET) maximum standardized uptake value $\left(\mathrm{SUV}_{\max }\right)>70 \%$, a normal-appearing endoscopic examination, and no residual disease on biopsy are predictive of pCR. However, approximately $30 \%$ of patients with these characteristics still harbor disease. Nevertheless, we have observed an institutional shift in the approach to esophageal SCC, wherein selective referral for surgery is chosen for patients with suspected residual disease and close observation is chosen for patients with a high likelihood of pCR. ${ }^{5}$ The effect of this approach on outcomes is unclear.

The purpose of this study was to assess outcomesoverall survival (OS), disease-free survival (DFS), and site-specific recurrence-between definitive CRT and trimodality treatment for patients who completed CRT for locally advanced esophageal SCC.

\section{METHODS}

\section{Study Population}

Patients with locally advanced esophageal SCC (clinical stage II-III) treated with either definitive CRT or trimodality treatment between 2000 and 2016 were included in the study. Patients were identified from a Memorial Sloan Kettering Cancer Center institutional database or a prospectively maintained thoracic surgical database. Patients with other cancers were included only if those cancers were considered cured or if that prognosis was better than their esophageal cancer prognosis. Patients with cancer of the cervical or upper thoracic esophagus (endoscopically measured up to $25 \mathrm{~cm}$ from the incisors) were excluded. Other exclusion criteria included clinical stage I or IV disease (according to the seventh edition of the American Joint Committee on Cancer Staging Manual); treatment consisting of radiation, chemotherapy, or surgery alone; a radiation dose of $<45 \mathrm{~Gy}$; chemotherapy alone used for induction; or a history of esophageal cancer. The final analysis cohort includes patients who completed CRT, defined as being alive with no progression of disease during treatment. This study was reviewed and approved by our institutional review board (approval: protocol 16-1631 conditionally approved July 21, 2016, approved December 13, 2016) 


\section{Variables}

Patient demographic characteristics, comorbidities, tumor histological features, stage of disease, treatment details, surgical complications, and recurrence and survival status were retrieved from a prospectively maintained surgical database or the patient's electronic medical record. Assessment of clinical stage was performed with esophagogastroduodenoscopy and biopsy, endoscopic ultrasound, computed tomography (CT), and PET. PET standardized uptake value (SUV) values were retrieved for preas well as post-treatment evaluation. Clinical stage was retrospectively classified according to the seventh edition of the American Joint Committee on Cancer Staging Manual. At the end of CRT, clinical response was evaluated using physical examination, clinical assessment of dysphagia, and PET/CT. Endoscopy with biopsy was selectively performed in patients with complete clinical response.

Recurrence was classified as local if disease was identified within the esophagus or stomach; as regional if disease was observed within the mediastinal, periesophageal, or gastric, celiac, and/or supraclavicular lymph nodes; and distant if disease was observed in other organs and/or retroperitoneal nodes.

Patients were grouped according to the treatment they received. Patients who were treated with definitive CRT and later underwent surgery for recurrence of disease were classified as patients who underwent salvage esophagectomy. For patients who underwent esophagectomy, pathological stage and response to treatment were determined according to the amount of residual viable tumor in the surgical specimen, as previously described. ${ }^{13}$ A pCR was defined as the absence of histological evidence of cancer in the surgical specimen.

\section{Statistical Analysis}

The definitive CRT and trimodality treatment groups were compared in terms of demographic, tumor, and clinical characteristics using Fisher exact test for categorical variables or the Wilcoxon rank sum test for continuous variables. Descriptive data were summarized as frequencies and percentages for categorical variables and medians and interquartile ranges for continuous variables. Because of the retrospective nature of this cohort, 2 issues were addressed: (1) potential selection bias for surgery; and (2) guaranteed survival time for the trimodality group. The first issue was addressed using propensity score-matching between definitive CRT and trimodality; the second issue was addressed by considering surgery as a time-dependent variable (described in the third paragraph of the Statistical Analysis section).

Propensity score-matching was conducted to overcome potential selection bias for the choice of treatment, by balancing treatment groups according to patient and pretreatment characteristics. Treatment groups were defined as receiving surgery after CRT (trimodality) or not receiving surgery after CRT (definitive CRT). Patients who received surgery as part of a salvage regimen after recurrence were considered to be definitive CRT patients and were used as potential controls for matching. The propensity score-defined as the probability of receiving trimodality treatment, given the covariates-was estimated using logistic regression. The covariates included age, sex, comorbidities (pulmonary, cardiac, diabetes, previous cancer), previous chest radiation, tumor location, histological grade (poor vs well/moderate), clinical stage (II vs III), induction chemotherapy, chemotherapy duration, and radiation dose ( $\geq 5040 \mathrm{vs}<5040 \mathrm{cGy})$. Year of treatment (before or after 2009) was considered a proxy for potential changes in clinical practices. It was included as an adjustment factor (or control variable) in all time-to-event analyses. A one-to-one "nearest neighbor" matching without replacement was performed using the MatchIt package in R (R Development Core Team, Vienna, Austria). The logit of the propensity score was used as the matching scale, and 0.2 times the $\mathrm{SD}$ of the logit (propensity score) was used as the initial matching caliper. ${ }^{14}$ The caliper width was reduced until a matched sample with optimal balance in covariates between groups was formed. Balance diagnostics after matching were evaluated by estimating the standardized mean difference (SMD). ${ }^{15}$ An SMD $<0.1$ was considered a negligible difference and was indicative of success of the matching procedure. ${ }^{16}$ Analyses account for matching either through paired tests (McNemar or Wilcoxon signed rank test) or with a gamma frailty term on the matched pairs in Cox regression models.

The primary objective was to evaluate the effect of trimodality treatment, compared with definitive CRT, on OS and DFS. OS was calculated from the end of CRT until death or last follow-up. Patients who received salvage surgery after recurrence were censored on the date of salvage surgery. The purpose of this approach was to evaluate only the time receiving CRT. DFS was calculated from the end of CRT until recurrence, death, or last follow-up. We also considered the issue of "guaranteed survival time": patients who received trimodality had to complete treatment and survive without further progression to receive surgery, whereas patients who received definitive CRT did not have this survival requirement. The longer survival requirement for the surgery patients might result in the CRT group unfairly appearing to have worse survival prognosis. ${ }^{17}$ To address this potential bias, surgery was considered a time-dependent variable, where all patients begin in the CRT group and switch to the trimodality group on the date of surgery (if any). This approach appropriately credits survival time before surgery to the CRT group.

A visual representation of OS and DFS stratified according to treatment group, in which trimodality treatment was treated as a time-dependent variable, was plotted using a nonparametric method by Simon and Makuch. ${ }^{18}$ To account for the propensity score-matched pairs, univariable and multivariable analyses for associations with OS and DFS were performed using Cox regression with a gamma frailty term, fixing year of treatment as an adjustment factor in addition to the treatment group (variable of interest). ${ }^{19}$

As a secondary objective, the types of recurrence that were associated with treatment were examined. Time to any recurrence was calculated from the end of CRT until the date of recurrence or of the last follow-up without detection of recurrence. If multiple recurrence types were detected at the same time, the patient was classified as having the most severe recurrence type (ie, distant $>$ regional $>$ local). We defined failure from the recurrence type of interest as events and failure from other recurrence types as censored observations. The same was done for each recurrence type. The cumulative incidence curves were generated from 1 minus the Kaplan-Meier estimates. We used cause-specific hazards Cox regression and performed nested likelihood ratio tests to obtain the $P$ value, evaluating surgery as a time-dependent variable, including year of treatment as an adjustment factor.

Two-sided $P<.05$ was considered statistically significant. Statistical analyses were performed using SAS 9.4 (SAS Institute Inc, Cary, NC) and R 3.2.4 (R Development Core Team).

\section{RESULTS \\ Demographic Characteristics}

We identified 491 patients with esophageal SCC treated between 2000 and 2016, of whom 232 met the inclusion criteria. A Consolidated Standards of Reporting Trials diagram with details on included and excluded patients is included as Figure E1. Definitive CRT was the primary treatment for 124 patients $(53 \%)$, whereas 108 patients underwent trimodality treatment $(47 \%)$. Patient characteristics are summarized in Table 1. Patients in the definitive CRT group were older and had a higher rate of comorbidities. The temporal distribution of treatment reflects our institutional change of practice: before 2009, most patients who were good surgical candidates were 
TABLE 1. Demographic and clinical characteristics pre- and postmatching

\begin{tabular}{|c|c|c|c|c|c|c|c|c|}
\hline \multirow[b]{2}{*}{ Characteristic } & \multicolumn{4}{|c|}{ Prematching } & \multicolumn{4}{|c|}{ Postmatching } \\
\hline & CRT & Trimodality & $P$ & SMD & CRT & Trimodality & $P$ & SMD \\
\hline $\mathrm{n}$ & 124 & 108 & & & 56 & 56 & & \\
\hline \multicolumn{9}{|l|}{ Matched variables } \\
\hline Median age (IQR), y & $70(63-76)$ & $60(56-67)$ & $<.001$ & 0.908 & $65(57-71)$ & $64.5(59-69)$ & 686 & 0.078 \\
\hline Median chemotherapy duration (IQR), mo & $2.3(1.7-2.8)$ & $2.1(1.3-2.5)$ & .006 & 0.385 & $2.2(1.6-2.6)$ & $2.3(1.4-2.7)$ & .87 & 0.108 \\
\hline Male sex & $68(55)$ & $58(54)$ & .97 & 0.023 & $30(54)$ & $30(54)$ & .99 & $<0.001$ \\
\hline Pulmonary & $15(12)$ & $11(10)$ & .80 & 0.061 & $6(11)$ & $5(9)$ & .99 & 0.060 \\
\hline Cardiac & $91(73)$ & $42(39)$ & $<.001$ & 0.741 & $32(57)$ & $31(55)$ & .99 & 0.036 \\
\hline Diabetes & $18(15)$ & $7(7)$ & .079 & 0.264 & $8(14)$ & $6(11)$ & .79 & 0.108 \\
\hline Previous cancer & $38(31)$ & $7(7)$ & $<.001$ & 0.654 & $7(13)$ & $6(11)$ & .99 & 0.056 \\
\hline Previous chest radiation & $11(9)$ & $3(3)$ & .095 & 0.262 & $1(2)$ & $2(4)$ & .99 & 0.111 \\
\hline Middle location & $64(52)$ & $46(43)$ & .22 & 0.181 & $22(39)$ & $24(43)$ & .85 & 0.073 \\
\hline Poor differentiation* & $49(42)$ & $33(33)$ & .21 & 0.192 & $22(39)$ & $21(38)$ & .99 & 0.037 \\
\hline Clinical stage III & $85(69)$ & $68(63)$ & .45 & 0.118 & $36(64)$ & $36(64)$ & .99 & $<0.001$ \\
\hline Induction chemotherapy & $87(70)$ & $57(53)$ & .010 & 0.363 & $37(66)$ & $36(64)$ & .99 & 0.037 \\
\hline Radiation dose $\geq 5040 \mathrm{cGy}$ & $115(93)$ & $96(89)$ & .43 & 0.134 & $53(95)$ & $53(95)$ & .99 & $<0.001$ \\
\hline \multicolumn{9}{|l|}{ Unmatched variables } \\
\hline Treatment after 2009 & $73(59)$ & $30(28)$ & $<.001$ & - & $31(55)$ & $16(29)$ & .007 & - \\
\hline Median $\mathrm{SUV}_{\max }$ post-treatment (IQR) & $3.2(0.0-5.2)$ & $3.5(0.8-5.2)$ & .47 & - & $3.1(0.0-5.2)$ & $3.8(0.0-7.0)$ & .33 & - \\
\hline
\end{tabular}

Unless otherwise noted, data are no. (\%). CRT, Chemoradiotherapy; trimodality, neoadjuvant chemoradiotherapy followed by surgery; $S M D$, standardized mean difference; $I Q R$, interquartile range; $S U V_{\max }$, maximum standardized uptake value. *Unknown for 16 patients prematching.

offered surgery $(61 \%$ patients received trimodality treatment), whereas after 2009, only patients with suspected persistence of disease were encouraged to undergo surgery ( $29 \%$ patients received trimodality treatment; $P<.0001)$. Most patients were evaluated with PET/CT before treatment and after completion of CRT. Patients treated at our institution received induction chemotherapy before CRT, because it has become our standard practice to change chemotherapy during concurrent radiation for patients assessed to be nonresponders to induction chemotherapy according to PET scan. ${ }^{20}$ Most patients treated at our institution received the same dose of radiation therapy (5040 cGy) independently of surgical plans. There were no major differences in post-treatment $\mathrm{SUV}_{\max }$ between the 2 groups. Of the patients who received definitive CRT, 17 underwent salvage surgery (16 for local and 1 for regional recurrence). Salvage surgery was abandoned in 2 patients determined to have unresectable disease. A comparative analysis of patients who underwent salvage surgery and those who underwent trimodality treatment showed a higher rate of grade $\geq 3$ pulmonary complications $(29 \%$ vs $11 \% ; P=.06)$ and 30 -day mortality $(18 \%$ vs $2 \%$; $P=.02)$ among patients who underwent salvage surgery (Table E1).

Among the patients who underwent trimodality treatment, the median time from end of CRT to surgery was 2 months (interquartile range, 1.6-2.9 months). The most common surgery was Ivor Lewis esophagectomy (64\% of cases), followed by 3 -hole (33\%), and transhiatal (3\%) esophagectomy. Esophagectomy was abandoned in 2 patients deemed to have unresectable disease; in 1 patient, only an R2 resection was possible. Postoperative 30-day mortality was $2 \% ; 27 \%$ of patients experienced overall grade $\geq 3$ complications. A pCR was achieved in 49 patients $(47 \%)$.

The propensity score-matching procedure yielded a balanced cohort of 112 patients-56 in each treatment group (Table 1). After matching, all 13 characteristics were balanced between the 2 groups, with the exception of chemotherapy duration (SMD $=0.108$ ), diabetes $(\mathrm{SMD}=0.108)$, and previous chest radiation $(\mathrm{SMD}=0.111)$. The 2 groups did not differ in other variables not included in the propensity score-matching, except that there were higher proportions of definitive CRT treated recently.

\section{Overall Survival}

In the matched cohort of 112 patients, there were 66 deaths. Median follow-up among survivors after the end of CRT was 2.3 years (range, 0.3-14.6 years). Median OS was 2.3 years $(95 \%$ confidence interval [CI], 1.5-3.5 years) for definitive CRT and 3.1 years (95\% CI, 2.1-8.3 years) for trimodality treatment. The 5-year OS was $29 \%(95 \% \mathrm{CI}$, $18 \%-49 \%)$ for definitive CRT and $45 \% \quad(95 \%$ CI, $33 \%-62 \%$ ) for trimodality treatment (Figure 1).

Univariable analysis results for association with OS are shown in Table 2. In multivariable analysis, trimodality treatment was significantly associated with improved OS (hazard ratio [HR], 0.57; 95\% CI, 0.34-0.97; $P=.039$ ), after year of treatment was controlled for. Among patients 


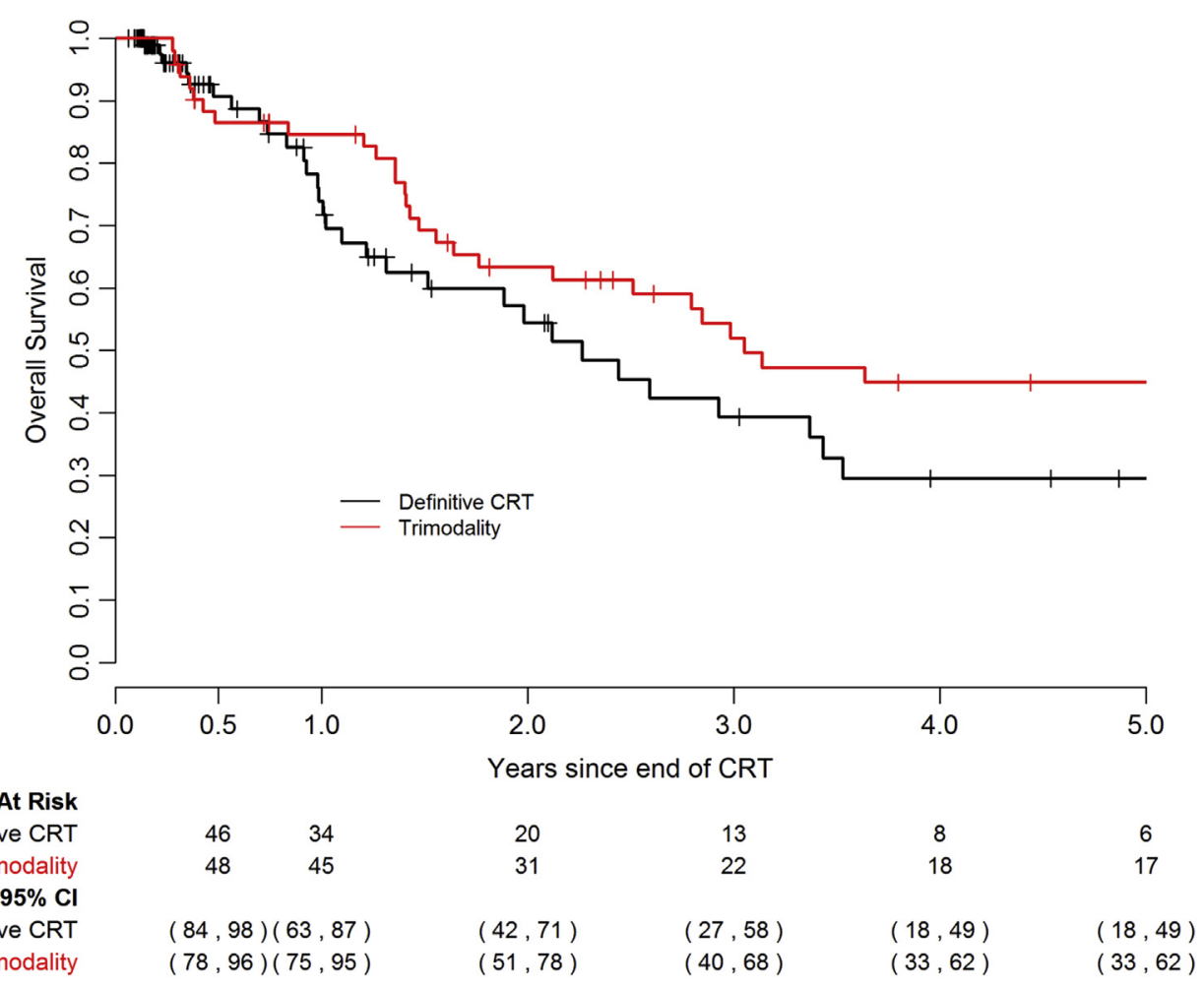

FIGURE 1. Overall survival, stratified according to treatment. $C R T$, Chemoradiotherapy; trimodality, neoadjuvant chemoradiotherapy followed by surgery; $C I$, confidence interval.

with available data on SUV after treatment $(n=69)$, the effect of trimodality treatment remained protective and was significant in a model controlling for year of treatment and $\mathrm{SUV}_{\max }$ post-treatment (HR, 0.40;P=.05). For sensitivity analyses, we included each of the 3 variables with an absolute standardized mean difference $>0.1$ into the final multivariable model for OS individually: chemotherapy duration, diabetes, and previous chest radiation. None of the 3 variables was significantly associated with OS. In addition, the protective effect of trimodality treatment was retained after the addition of the imbalanced variables (Table E2).

\section{Disease-Free Survival}

There were 51 recurrences and 80 recurrence or death events in the matched cohort. Median DFS was 1.0 years (95\% CI, 0.7-1.7 years) for definitive CRT and 1.8 years (95\% CI, 1.2-6.9 years) for trimodality treatment. The 5-year DFS was $23 \%(95 \%$ CI, $14 \%-40 \%)$ for definitive CRT and $40 \%(95 \%$ CI, 29\%-56\%) for trimodality treatment (Figure 2). Results of the univariable analysis for association with DFS are shown in Table 3. In multivariable analysis, trimodality treatment was significantly associated with improved DFS (HR, 0.51; 95\% CI, 0.32-0.83; $P=.007$ ), after year of treatment was controlled for. Among patients with available post-CRT $\mathrm{SUV}_{\text {max }}$ data $(\mathrm{n}=69)$, the effect of trimodality treatment remained protective after controlling for year of treatment and $\mathrm{SUV}_{\max }$ post-treatment (HR, 0.55; $\left.P=.065\right)$. In sensitivity analyses, of the 3 variables with an absolute standardized mean difference $>0.1$, none was significantly associated with DFS. In addition, the protective effect of trimodality was retained after the addition of the imbalanced variables (Table E3).

\section{Recurrence}

Twelve patients had local recurrence only, 12 had regional recurrence, and 27 had distant recurrence. The 5 -year cumulative incidence of local recurrence was $38 \%$ $(95 \%$ CI, $15 \%-55 \%)$ for patients treated with definitive CRT, compared with $0 \%$ for patients treated with trimodality $(P<.001$; Figure 3$)$. Regional and systemic recurrence rates did not significantly differ between the 2 groups (5-year cumulative incidence of regional recurrence was $19 \%$ vs $18 \%$ and distant recurrence was $38 \%$ vs $27 \%$ for CRT vs trimodality, respectively; Figure 4, $A$ and $B$ ).

\section{DISCUSSION}

In this study, we sought to evaluate the role of surgery for curative intent after CRT in patients with locally advanced esophageal SCC. We found a statistically significant decrease in risk of recurrence, particularly local recurrence, and increased DFS and OS among patients who received 
TABLE 2. Cox regression analysis for association between factors and OS using matched data*

\begin{tabular}{llll}
\hline \multicolumn{1}{c}{ Factor } & HR & 95\% CI & $\boldsymbol{P}$ \\
\hline Treatment, trimodality vs CRT & 0.57 & $0.34-0.97$ & .039 \\
Age per year & 1.02 & $0.99-1.04$ & .263 \\
\hline Chemotherapy duration per month & 0.9 & $0.65-1.24$ & .514 \\
\hline Sex, male vs female & 1.27 & $0.78-2.08$ & .338 \\
\hline Pulmonary, yes vs no & 1.62 & $0.69-3.8$ & .268 \\
Cardiac, yes vs no & 1.27 & $0.78-2.08$ & .343 \\
\hline Diabetes, yes vs no & 1.97 & $0.95-4.08$ & .068 \\
\hline Previous cancer, yes vs no & 0.81 & $0.38-1.71$ & .58 \\
\hline Previous chest radiation, yes vs no & 1.93 & $0.46-8.08$ & .367 \\
\hline Location, mid vs distal & 1.19 & $0.73-1.94$ & .476 \\
\hline Differentiation, poor vs well/moderate & 1.35 & $0.83-2.21$ & .224 \\
Clinical stage, 3 vs 2 & 1 & $0.61-1.66$ & .993 \\
\hline Induction chemotherapy, yes vs no & 0.82 & $0.49-1.35$ & .43 \\
\hline Radiation dose, $\geq 5040$ vs $<5040$ & 0.82 & $0.3-2.28$ & .706 \\
\hline SUV ${ }_{\text {max }}$ post-treatment & 1.06 & $0.97-1.15$ & .18 \\
\hline
\end{tabular}

$H R$, Hazard ratio; $C I$, confidence interval; trimodality, neoadjuvant chemoradiotherapy followed by surgery; $C R T$, chemoradiotherapy; $S U V_{\max }$, maximum standardized uptake value. *Year of treatment (before vs after 2009) and a gamma frailty term on the matched pairs were included in the analysis of each variable.

surgery after induction CRT. Moreover, trimodality treatment was an independent factor associated with prolonged DFS and OS. Because definitive CRT has become the most common treatment for locally advanced esophageal SCC in the United States, despite national guidelines recommending trimodality treatment for patients suitable for surgery, our results are particularly relevant. ${ }^{4}$ The results of 2 randomized, controlled trials from the previous decade, showing no benefit in patients who received surgery, have certainly contributed to the belief that surgery does not offer much advantage and potentially leads to increased morbidity and impaired quality of life. ${ }^{6,7}$ However, these trials have been strongly criticized, and the quality of their evidence has not been considered appropriate to generate recommendations for best treatment practices. ${ }^{3}$ In the trial reported by Stahl et al from Germany, mortality in the surgical group was $13 \%$ overall, with most of the deaths occurring during the perioperative period $(11 \%) .^{7}$ This is significantly higher than the perioperative mortality reported by highly specialized and high-volume centers ${ }^{21-25}$ and the $2 \%$ in this study. Moreover, patients in the surgical arm received only 40 Gy of radiation, whereas patients in the nonsurgical arm received 50 Gy. Only $66 \%$ of patients randomized to surgery actually went on to receive surgery, and their 3-year OS of 31\% was much lower than the $58 \%$ reported in the CROSS trial and the $52 \%$ $(95 \% \mathrm{CI}, 40 \%-68 \%)$ in this study. In the French trial reported by Bedenne et al, only patients who responded to CRT were randomized, and the study included patients

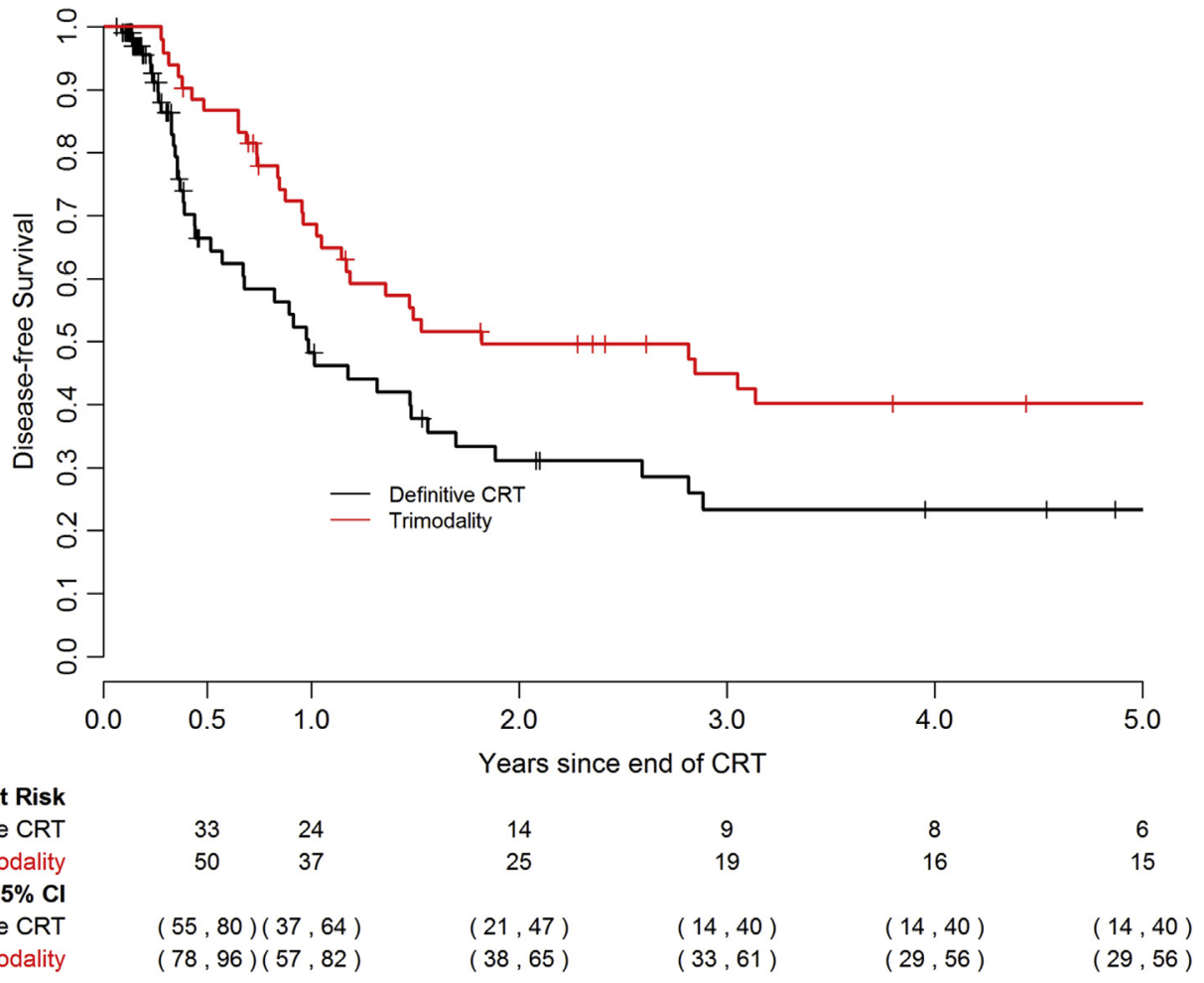

FIGURE 2. Kaplan-Meier curve showing disease-free survival, stratified according to treatment group. CRT, Chemoradiotherapy; trimodality, neoadjuvant chemoradiotherapy followed by surgery; $C I$, confidence interval. 
TABLE 3. Cox regression analysis of disease-free survival using matched data*

\begin{tabular}{llcl}
\hline \multicolumn{1}{c}{ Factor } & HR & $\mathbf{9 5} \%$ CI & $\boldsymbol{P}$ \\
\hline Treatment, trimodality vs CRT & 0.51 & $0.32-0.83$ & .007 \\
Age per year & 1.01 & $0.99-1.04$ & .392 \\
\hline Chemotherapy duration per month & 0.86 & $0.65-1.15$ & .31 \\
\hline Sex, male vs female & 1.38 & $0.88-2.17$ & .157 \\
\hline Pulmonary, yes vs no & 1.78 & $0.87-3.63$ & .113 \\
\hline Cardiac, yes vs no & 1.28 & $0.81-2$ & .288 \\
\hline Diabetes, yes vs no & 1.5 & $0.78-2.89$ & .223 \\
\hline Previous cancer, yes vs no & 0.87 & $0.43-1.76$ & .706 \\
\hline Previous chest radiation, yes vs no & 1.67 & $0.4-6.94$ & .479 \\
\hline Location, mid vs distal & 0.94 & $0.6-1.47$ & .79 \\
\hline Differentiation, poor vs well/moderate & 1.37 & $0.88-2.15$ & .163 \\
\hline Clinical stage, 3 vs 2 & 1.08 & $0.68-1.71$ & .749 \\
\hline Induction chemotherapy, yes vs no & 0.71 & $0.45-1.13$ & .15 \\
\hline Radiation dose, $\geq 5040$ vs $<5040$ & 0.75 & $0.3-1.86$ & .532 \\
\hline SUV ${ }_{\text {max }}$ post-treatment & 1.04 & $0.96-1.12$ & .343 \\
\hline
\end{tabular}

$H R$, Hazard ratio; $C I$, confidence interval; trimodality, neoadjuvant chemoradiotherapy followed by surgery; $C R T$, chemoradiotherapy; $S U V_{\max }$, maximum standardized uptake value. *Year of treatment (before vs after 2009) and a gamma frailty term on the matched pairs were included in the analysis of each variable.

with SCC and adenocarcinoma. Again, there was a high 90day mortality $(9 \%)$ in the surgical arm, a low rate of complete resection $(75 \%)$, and a 2 -year survival of $34 \%$, which is significantly lower than the $67 \%$ reported in the CROSS trial and the $63 \%(95 \% \mathrm{CI}, 51 \%-78 \%)$ in this study. ${ }^{2,6}$ Conversely, several nonrandomized studies from the United States and the East, where this cancer is much more prevalent, have reported results in accordance with ours. Nomura et al and the Japan Clinical Oncology Group (JCOG) pooled data from 2 previous prospective trials of patients with locally advanced esophageal SCC treated with either definitive CRT (JCOG 9906) ${ }^{26}$ or trimodality treatment (JCOG 9907) ${ }^{27}$ and reported significantly improved progression-free survival and OS for patients treated with esophagectomy (definitive CRT vs trimodality: adjusted HR, 1.76 [95\% CI, 1.3-2.5] vs 1.72 [95\% CI, 1.2-2.5]). ${ }^{28}$ Similarly, Liao et al reported statistically significant improvements in OS, DFS, and locoregional control with esophagectomy in a matched-pair analysis of patients with stage II and III esophageal cancer.

In this study, we found that local recurrence was the main reason for treatment failure in patients who received definitive CRT. The 5-year cumulative incidence of distant recurrence was, in fact, similar between groups $(38 \%$ for definitive CRT vs $27 \%$ for trimodality), suggesting that local control might influence survival in these patients. This result is also supported by the German as well as French randomized trials mentioned previously, which showed higher local control rates and higher DFS with surgery. The difference in 5-year cumulative incidence of local recurrence between definitive CRT $(38 \%)$ and trimodality treatment $(0 \%)$ highlights the inability to accurately assess for tumor response and the inaccuracy of clinical complete response. The differences in DFS between the 2 groups were likely driven by worse local control in the definitive CRT group.

We do not, at present, have a reliable clinical tool to preoperatively identify $\mathrm{pCR}$ - assuming that $\mathrm{pCR}$ is meaningful of absence of locoregional disease. Even with a negative endoscopic examination, benign histological findings on biopsy, and significantly decreased $\mathrm{SUV}_{\max }$ after treatment, up to $30 \%$ of patients harbor disease in their esophagus. Waiting longer before performing surgery might seem appealing in that it allows for better selection of patients with residual disease or recurrence; however, in our experience, salvage esophagectomy is associated with higher morbidity and worse overall outcomes and should not be taken lightly. Previous studies on this subject have shown contradictory results. ${ }^{29-33}$ The delayed effects of radiation might not only eliminate dissection planes but might also significantly impair lung function and overall healing. The overall pCR rate in this study was $47 \%$, which is similar to the $49 \%$ reported in the CROSS trial. Overall, more than half of patients who underwent surgery had residual disease found in their specimen. This is important information that should be shared with patients and providers.

Among the limitations of this study is its retrospective design, the intent of treatment cannot be known and likely introduced selection bias- the most important being the direction of healthy patients to the trimodality group. Although this trend was probably true before 2009, the matching procedure takes into account clinically relevant differences that were observed. After 2009, most patients directed to surgery were those with findings suspected to be persistent disease; therefore, patients with the worst prognosis were potentially selected into the trimodality group. Nevertheless, even with a higher percentage of nonresponders in the trimodality group ( $66 \%$ vs $47 \%)$, these patients had higher OS and DFS. Bias because of the survival requirement among the surgery group was also a concern; to address this, we excluded patients from the CRT group who were unable to complete CRT because of early death or recurrence to ensure adequate follow-up after CRT and to have comparable groups. Thus our results can be generalizable to patients who survive chemoradiation therapy without progression of disease. Another important limitation was the use of different chemotherapy agents during the study period and the use of induction chemotherapy before CRT and PET-directed chemotherapy only for patients treated at our institution. Moreover, our study cohort might not match the United States population in terms of the 


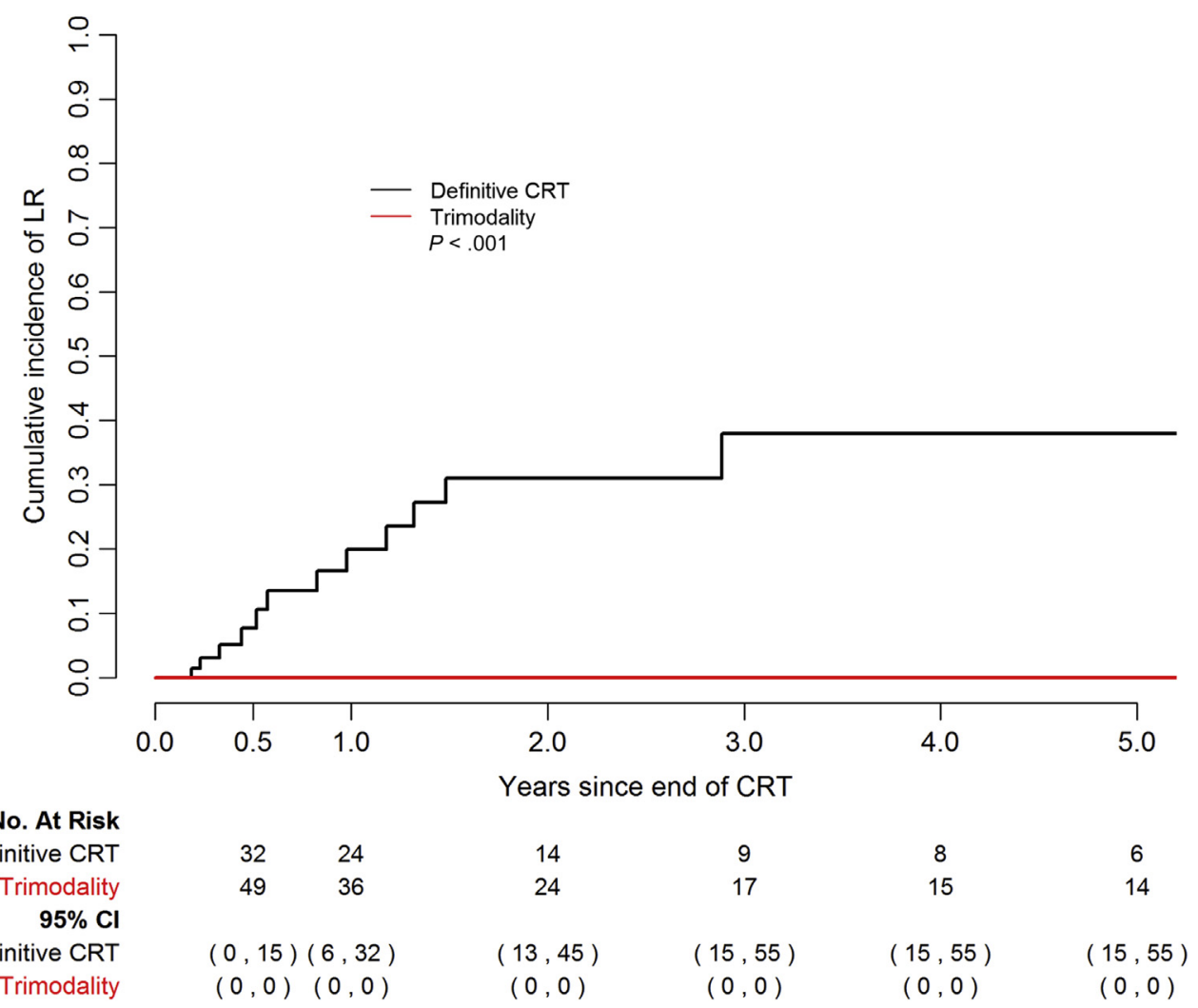

FIGURE 3. Cumulative incidence of local recurrence $(L R)$. CRT, Chemoradiotherapy; trimodality, neoadjuvant chemoradiotherapy followed by surgery; $C I$, confidence interval.

distribution of stage of esophageal cancer patients, because our data are from a tertiary cancer treatment center and only patients with locally advanced disease were considered for our study.

Overall, this study has several strengths. Only patients with esophageal SCC who completed CRT were included, and, in most cases, clinical staging included PET and endoscopic ultrasound. There was no difference in radiation dose between the 3 groups, and all patients received a dose of at least $45 \mathrm{~Gy}$. Even if the median post-treatment $\mathrm{SUV}_{\max }$ was approximately 3 in both groups, most patients selected for observation after CRT had a higher PET-SUV reduction (the rate of SUV reduction $>70 \%$ was $66 \%$ for the definitive CRT group and $47 \%$ for the trimodality group in the

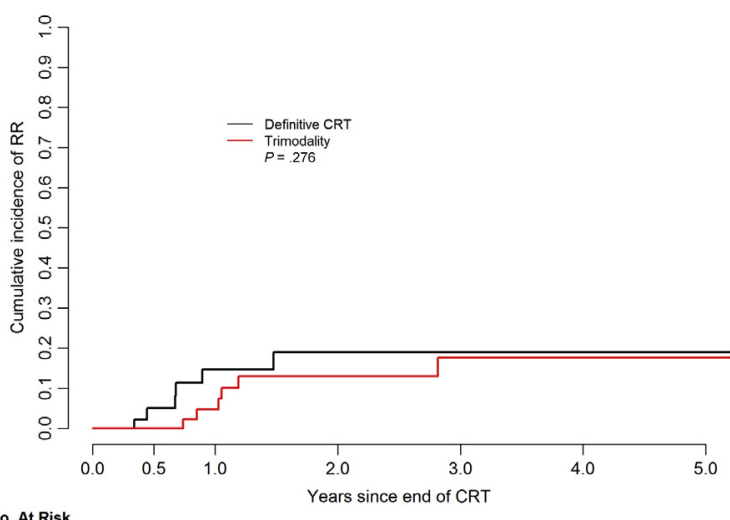

\begin{tabular}{|c|c|c|c|c|c|c|}
\hline \multirow{3}{*}{$\begin{array}{l}\text { No. At Risk } \\
\text { Definitive CRT }\end{array}$} & \multirow{2}{*}{\multicolumn{6}{|c|}{ (2) }} \\
\hline & & & & & & \\
\hline & $\begin{array}{l}32 \\
49\end{array}$ & $\begin{array}{l}24 \\
36\end{array}$ & 14 & 9 & ${ }_{15}^{8}$ & $\begin{array}{c}6 \\
14\end{array}$ \\
\hline $\begin{array}{r}\text { Trimodality } \\
\quad 95 \% \mathrm{Cl}\end{array}$ & 49 & 36 & 24 & & 15 & \\
\hline Definitive CRT & $(0,12)$ & $(2,26)$ & $(4,32)$ & $(4,32)$ & $(4,32)$ & $(4,32)$ \\
\hline Trimodality & $(0,0$ & $(0,11)$ & $(2,23)$ & $(3,30)$ & $(3,30)$ & $(3,30)$ \\
\hline
\end{tabular}

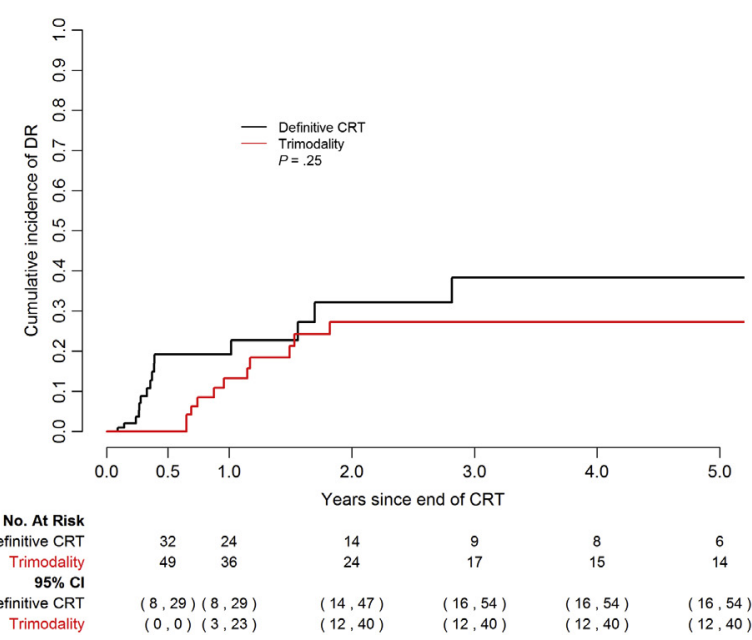

FIGURE 4. Cumulative incidence of regional (A) and distant (B) recurrence. RR, Regional recurrence; $C R T$, chemoradiotherapy; trimodality, neoadjuvant chemoradiotherapy followed by surgery; $C I$, confidence interval; $D R$, distant recurrence. 


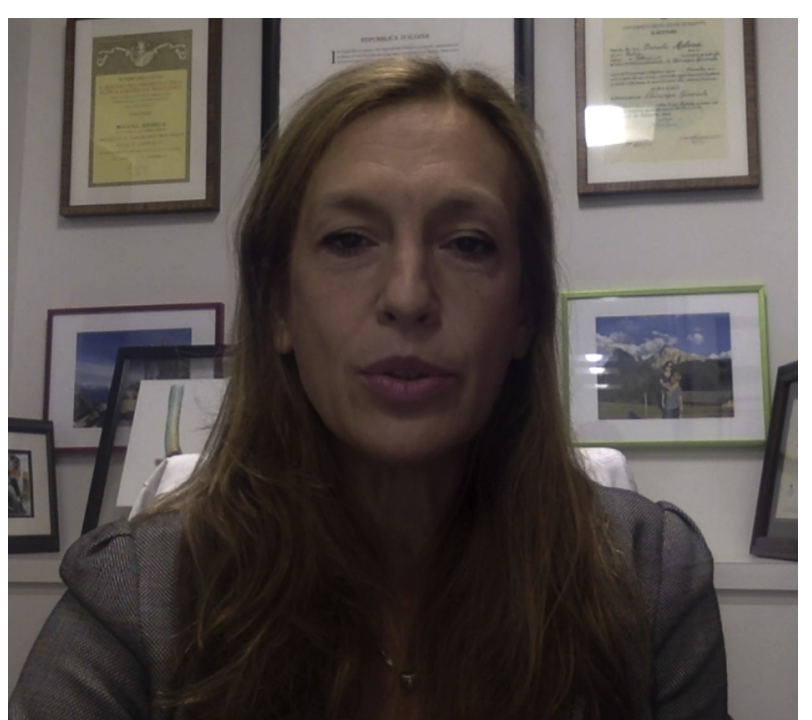

VIDEO 1. Daniela Molena, MD, discussing the implications of the study. Video available at: http://www.jtcvsonline.org/article/S0022-5223(18) 30370-2/fulltext.

matched groups, respectively), perhaps highlighting a higher rate of clinical response to treatment in the definitive CRT group. Despite this, patients who underwent surgery still had better outcomes than patients treated with definitive CRT.

\section{CONCLUSIONS}

Surgery should be considered after completion of CRT for treatment of esophageal SCC in patients who are fit for surgery (Video 1). Surgery was associated with a decreased probability of local recurrence and increased DFS and OS. Because there is not, at present, a reliable way to preoperatively identify patients with $\mathrm{pCR}$, and because salvage surgery might be associated with increased morbidity and mortality, the potential advantages of surgical resection after CRT should be reviewed and discussed with patients who undergo treatment for esophageal SCC.

\section{Webcast}

You can watch a Webcast of this AATS meeting presentation by going to: https://aats.blob.core.windows.net/media/17AM/ 2017-05-02/BallroomABC/05-02-17_BallroomABC_1103_ Barbetta.mp4.

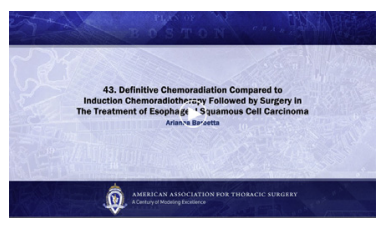

\section{Conflict of Interest Statement}

Authors have nothing to disclose with regard to commercial support.

\section{References}

1. van Hagen P, Hulshof MC, van Lanschot JJ, Steyerberg EW, van Berge Henegouwen MI, Wijnhoven BP, et al. Preoperative chemoradiotherapy for esophageal or junctional cancer. N Engl J Med. 2012;366:2074-84.

2. Van Heijl M, van Lanschot JJ, Koppert LB, van Berge Henegouwen MI, Muller K, Steyeberg EW, et al. Neoadjuvant chemoradiation followed by surgery versus surgery alone for patients with adenocarcinoma or squamous cell carcinoma of the esophagus (CROSS). BMC Surg. 2008;8:21.

3. National Comprehensive Cancer Network. NCCN Guidelines for Treatment of Cancer by Site: Esophageal Cancer. Available at: https://www.ncen.org/ professionals/physician_gls/pdf/esophageal.pdf. Accessed March 10, 2017.

4. Molena D, Miloslawa S, Blackford AL, Lidor AO. Esophageal cancer treatment is underutilized among elderly patients in the USA. J Gastrointest Surg. 2017;21: 126-36.

5. Molena D, Sun HH, Badr AS, Mungo B, Sarkaria IS, Adusumilli PS, et al. Clinical tools do not predict pathological response in patients with esophageal squamous cell cancer treated with definitive chemoradiotherapy. Dis Esophagus. 2014;27:355-9.

6. Bedenne L, Michel P, Bouché O, Milan C, Mariette C, Conroy T. Chemoradiation followed by surgery compared with chemoradiation alone in squamous cancer of the esophagus: FFCD 9102. J Clin Oncol. 2007;25:1160-8.

7. Stahl M, Stuscke M, Lehamann N, Meyer HJ, Walz MK, Siegfried S, et al. Chemoradiation with and without surgery in patients with locallly advanced squamous cell carcinoma of the esophagus. J Clin Oncol. 2005;23:2310-7.

8. Hategan M, Cook N, Prewett S, Hindmarsh A, Qian W, Gillian D. Trimodality therapy and definitive chemoradiotherapy for esophageal cancer: a single-center experience and review of the literature. Dis Esophagus. 2015; 28:612-8.

9. Liao Z, Zhang Z, Jin J, Ajani JA, Swisher SG, Stevens CW, et al. Esophagectomy after concurrent chemoradiotherapy improves locoregional control in clinical stage II or III esophageal cancer patients. Int J Radiat Oncol Biol Phys. 2004; 60:1484-93.

10. Liu SL, Qui B, Luo GY, Liang Y, Zheng YZ, Chen ZL, et al. TNM staging matched-pair comparison of surgery after neoadjuvant cheradiotherapy, surgery alone and definitive chemoradiotherapy for thoracic esophageal squamous cell carcinoma. J Cancer. 2017;8:683-90.

11. Nomura M, Oze I, Kodaira T, Abe T, Komori A, Narita Y. Comparison between surgery and definitive chemoradiotherapy for patients with resectable esophageal squamous cell carcinoma: a propensity score analysis. Int J Clin Oncol. 2016;21: 890-8.

12. Chen FM, Chen PT, Lu MS, Lee CP, Chen WC. Survival benefit of surgery to patients with esophageal squamous cell carcinoma. Sci Rep. 2017;7:46139.

13. Rizk NP, Seshan VE, Bains MS, Ilson DH, Minsky BD, Tang L, et al. Prognostic factors after combined modality treatment of squamous cell carcinoma of the esophagus. J Thorac Oncol. 2007;2:1117-23.

14. Austin PC. Optimal caliper widths for propensity-score matching when estimating differences in means and differences in proportions in observational studies. Pharm Stat. 2011;10:150-61.

15. Austin P. An introduction to propensity score methods for reducing the effects of confounding in observational studies. Multivariate Behav Res. 2011;46:399-424.

16. Normand SL, Landrum MB, Guadagnoli E, Ayanian JZ, Ryan TJ, Cleary PD, et al. Validating recommendations for coronary angiography following an acute myocardial infarction in the elderly: a matched analysis using propensity scores. J Clin Epidemiol. 2001;54:387-98.

17. Anderson JR, Cain KC, Gelber RD. Analysis of survival by tumor response. J Clin Oncol. 1983;1:710-9.

18. Simon R, Makuch RW. A non-parametric graphical representation of the relationship between survival and the occurrence of an event: application to responder versus non-responder bias. Stat Med. 1984;3:35-44.

19. Therneau TM, Grambsch PM, Pankratz VS. Penalized survival models and frailty. J Comput Graph Stat. 2003;12:156-75.

20. Ilson DH, Minsky BD, Ku GY, Rusch V, Rizk N, Shah M, et al. Phase 2 trial of induction and concurrent chemoradiotherapy with weekly irinotecan and cisplatin followed by surgery for esophageal cancer. Cancer. 2012;118:2820-7. 
Portale G, Hagen JA, Peters JH, Chan LS, DeMeester SR, Gandamihardja TA, et al. Modern 5-year survival of resectable esophageal adenocarcinoma: single institution experience with 263 patients. J Am Coll Surg. 2006;202:588-96.

22. Hulscher JB, van Sandick JW, de Boer AG, Wijnhoven BP, Tijssen JG, Fockens P, et al. Extended transthoracic resection compared with limited transhiatal resection for adenocarcinoma of the esophagus. N Engl J Med. 2002;347:1662-9.

23. Rentz J, Bull D, Harpole D, Bailey S, Neumayer L, Pappas T, et al. Transthoracic versus transhiatal esophagectomy: a prospective study of 945 patients. $J$ Thorac Cardiovasc Surg. 2003;125:1114-20.

24. Berry MF, Atkins BZ, Tong BC, Harpole DH, D'Amico TA, Onaitis MW. A comprehensive evaluation for aspiration after esophagectomy reduces the incidence of postoperative pneumonia. J Thorac Cardiovasc Surg. 2010;140: 1266-71.

25. Orringer MB, Marshall B, Chang AC, Lee J, Pickens A, Lau CL. Two thousand transhiatal esophagectomies: changing trends, lesson learned. Ann Surg. 2007; 246:363-72.

26. Kato K, Muro K, Minashi K, Ohtsu A, Ishikura S, Boku N, et al. Phase II study of chemoradiotherapy with 5-fluorouracil and cisplatin for stage II-III esophageal squamous cell carcinoma: JCOG trial (JCOG 9906). Int J Radiat Oncol Biol Phys. 2011;8:684-90

27. Ando N, Kato H, Igaki H, Shinoda M, Ozawa S, Shimizu H, et al. A randomized trial comparing postoperative adjuvant chemotherapy with cisplatin and 5-fluorouracil versus preoperative chemotherapy for localized advanced squamous cell carcinoma of the thoracic esophagus (JCOG9907). Ann Surg Oncol. 2012;19:68-74.

28. Nomura M, Kato K, Ando N, Ohtsu A, Muro K, Igaki H, et al. Comparison between neoadjuvant chemotherapy followed by surgery and definitive chemoradiotherapy for overall survival in patients with clinical stage II/III esophageal squamous cell carcinoma (JCOG 1406-A). Jpn J Clin Oncol. 2017; 47:480-6.

29. Miyata H, Yamasaki M, Takiguchi S, Nakajima K, Fujiwara Y, Nishida T, et al. Salvage esophagectomy after definitive chemoradiotherapy for thoracic esophageal cancer. J Surg Oncol. 2009;100:442-6.

30. Markar S, Gronnier C, Duhamel A, Pasquer A, Thereaux J, du Rieu MC, et al. Salvage surgery after chemoradiotherapy in the management of esophageal cancer: is it a viable therapeutic option? J Clin Oncol. 2015;33:3866-73.

31. Swisher SG, Marks J, Rice D. Salvage esophagectomy for persistent or recurrent disease after definitive chemoradiation. Ann Cardiothorac Surg. 2017;6:144-51.

32. Farinella E, Safar A, Nasser HA, Bouazza F, Liberale G, Paesmans M, et al. Salvage esophagectomy after failure of definitive radiochemotherapy for esophageal cancer. J Surg Oncol. 2016;114:833-7.

33. Hofstetter WL. Salvage esophagectomy. Thorac Dis. 2014;6(Suppl 3):S341-9.

Key Words: esophageal squamous cell carcinoma, definitive chemoradiotherapy, neoadjuvant treatment, trimodality treatment, esophagectomy, recurrence, pathological complete response

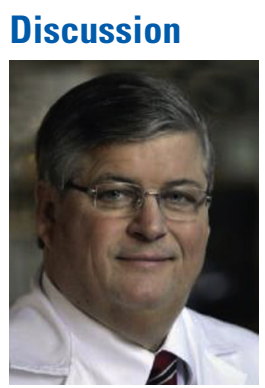

Dr David J. Sugarbaker (Waco, Tex). Thank you, Dr Molena, for an outstanding contribution to the literature regarding the trimodality therapy of squamous cell carcinoma and thank you for the excellent and concise and clear presentation.

The Memorial Hospital in New York has for years made major contributions to the field of esophageal surgery, and I think it is particularly fitting that we are hearing about squamous cell carcinoma when as we saw in the film on the history of the AATS that it was indeed the cause for the first resection by Torek at the beginning.

I would like to say a few things. Squamous cell carcinoma of the esophagus has become a relatively rare disease in North America, and it is particularly sensitive to cisplatinum-based treatment strategies as well as radiotherapy, particularly with concurrent radiation chemotherapy.

I have 5 questions and I will take them one at a time. First, how did you your group decide which patients were treated with chemoradiotherapy from the beginning and which patients were going to be treated with trimodality therapy? How was that decision made and how was it made here in terms of how you evaluated the medical record and what sort of a process do you have for multimodality evaluation of patients?

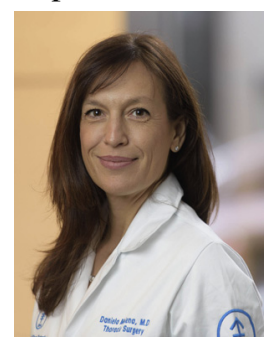

Dr Daniela Molena (New York, NY). This is a very interesting question Dr Sugarbaker. We have noticed a very important shift in the treatment of esophageal squamous cell cancer at our institution. Initially, patients were treated with trimodality intent (ie, chemotherapy and radiation followed by surgery), but since we have shown a high pCR rate in this population, often the oncologists recommend observation for patients who had a very good clinical response. In a previous paper however, we have shown to be able to correctly guess pCR in approximately $70 \%$ of patients and therefore considering surgery in patients with good functional status is important.

This is a retrospective study, so it is impossible to account for all selection bias, but we tried to create homogeneous groups of patients that were treated one way or the other to see if there was a difference in terms of outcome.

Probably in the latest phase of our experience, most patients who went to surgery were patients with less than optimal response on PET so you would think these patients would have had worse outcome after surgery but they instead did better than patients with clinical CR.

Dr Sugarbaker. My next question is, because salvage esophagectomy made up part of the surgical cohort and the group that underwent salvage obviously had to recur as detected by subsequent PET scan, how do you interpret surgery for recurrent squamous cell carcinoma of the esophagus versus surgery as a matter of course after chemoradiotherapy?

Dr Molena. This is another very important question, because a lot of physicians believe that even if we don't operate right away, the outcome is going to be the same if we promptly diagnose early local recurrence. There are very conflicting published data in the literature; the 
surgeons at M.D. Anderson showed that salvage esophagectomy has equivalent results. This has not been proven in our study, and we think that there is a double reason for this.

One problem is that having recurrent disease is a demonstration of aggressive tumor physiology, so those patients are selected out as having a bad outcome. Second, the operation is more difficult after a longer interval from definitive chemotherapy and radiation, especially for patients with midthoracic esophageal disease, where the esophagus is tightly surrounded by unresectable vital structures. So although it might be true that there is no difference for distal esophageal disease, the high prevalence of midthoracic disease in our series possibly contributed to the high rate of mortality and morbidity in our group.

Dr Sugarbaker. You have stated in your report that there has been a change in the approach to squamous cell carcinoma of the midesophagus, lower esophagus stage II and III over the years. What would you attribute this change in the initial approach away from adjuvant surgery?

Dr Molena. We had published a report a few years ago where we looked at our pathological complete responders (and let's assume that pCR is equivalent to cure) and we have seen that patients that had a decrease of $75 \%$ of their SUV after treatment and negative biopsy on endoscopy had a likelihood, approximately $70 \%$, to have a pathological complete response. Now, I interpreted that as $30 \%$ of those patients still have residual disease. Our oncologists interpreted that as most patients will have a pathological complete response, and so that has shifted our treatment paradigm.

Dr Sugarbaker. One last question. How do you think that you will incorporate these results in the practice at the Memorial Hospital moving forward?

Dr Molena. First of all, we need to really be involved early in the decision-making process with these patients and offer esophagectomy to young and healthy patients with low surgical risk. Second, I think we need to look at patients who have a pathological complete response but also long-term survivors and see if we can identify those earlier in the history of their disease, likely with biomarkers or genetic testing.

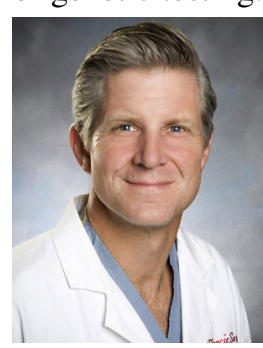

Dr Scott Swanson (Boston, Mass). That was an excellent presentation and discussion. Two questions, and you alluded to the first one a little bit. The mortality for salvage, do you have anymore details about what caused the deaths and was it specifically related to an intraoperative complication? Number two, how many of these cohorts were done minimally invasively? Thanks.

Dr Molena. The mortality was due to complications. Most of these patients had postoperative pulmonary complications and a much higher leak rate than the patients in the trimodality group. There were no intraoperative deaths but there were 2 patients who were unresectable at surgery.

In terms of minimally invasive approach, we have recently increased the number of minimally invasive operations and now we do a little over $50 \%$ esophagectomy with this approach. This was not true in the initial phase of our study when most of the patients were treated with open surgery.

Dr Swanson. So the percentage of that cohort that was done minimally invasive was?

Dr Molena. Approximately $10 \%$ of the entire cohort.

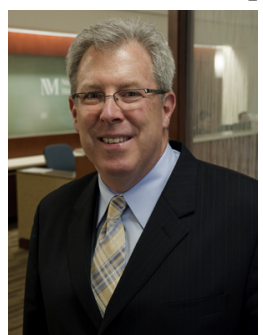

Dr Malcolm M. Decamp (Chicago, Ill). Congratulations on shedding light on an important problem. I think our medical oncologists think that squamous cell carcinoma of the esophagus is salvaged very much like head and neck, and it is clearly a different playing field for us as thoracic surgeons.

Can you comment on the pattern of failure, which might be an important thing to look at. Of your definitive chemoradiation patients, how many of those patients went on to develop systemic recurrences? You obviously operated on the ones that just had local recurrences.

Dr Molena. There was no difference in the 2 groups as far as systemic disease. Approximately $20 \%$ of patients will develop systemic recurrence, and we didn't notice any difference in the definitive versus the trimodality group. The significant difference in recurrence was only seen for local disease.

Dr Decamp. Then the follow-up observation is that obviously PET is not the perfect restaging tool, and we know that EUS after induction therapy also is not very predictive; because those ultrasound planes melt together. Can you speculate on what other tools we might use, perhaps molecularly, to better understand who is going to really benefit from surgery?

Dr Molena. We have shown in a previous study that $50 \%$ patients with negative endoscopic biopsy still harbor disease. We are looking at circulating tumor cells, and inflammatory markers and maybe we will increase our accuracy in detecting residual disease. I also want to note that we often misinterpret pCR as cure. These patients still recur over $40 \%$ of the time. So these are patients that might have disease harbored in a different location or the 
technology we have thus far to evaluate our surgical specimens is not perfect.

Dr Decamp. I think that is critical, because the mucosa is just not a deep enough sample. Thank you.

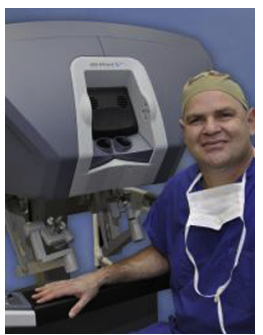

Dr Benny Weksler (Memphis, Tenn). Daniela, congratulations, on a great presentation and timely data. I really have 2 questions and maybe I have missed them. How many patients had lower esophageal squamous cell carcinoma versus midesophagus, and was the number of those patients the same in both groups? And the second question is, what was your R0 resection rate in the surgical arm?

Dr Molena. We had 54\% mid esophageal and 46\% distal esophageal cancer in the definitive group whereas we had $43 \%$ mid and $57 \%$ distal in the trimodality group. These numbers were not significantly different. Our complete resection rate was $93 \%$.

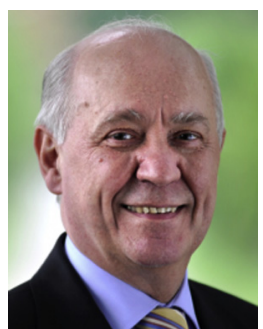

Dr Toni Lerut (Leuven, Belgium). A great study, Daniela, and thank you very much, great material. You just alluded to predictors for a complete response like SUV, and you can turn the question around, and I don't know whether it was within the scope of your study to look at predictors for recurrence or early recurrence like the $\mathrm{T}$ stage, the $\mathrm{N}$ stage, the grading. I can imagine that the T3 N0 is a different thing than a T2 N2 or grade 3 . Can you comment on that?

Dr Molena. Stage, initial, and post-treatment SUV uptake and tumor differentiation were not predictors of recurrence in our study. We considered factors that could have been associated with recurrence in a multivariable model and surgery was the only independent variable predicting recurrence.

Dr Lerut. But nothing out of the original clinical stages, no data?

Dr Molena. There was not. We looked at the original clinical staging. There was no influence in the outcome in terms of recurrence.

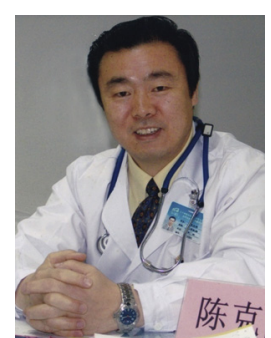

Dr Ke-Neng Chen (Beijing, China). First, congratulations! Dr Molena. Because the histology type of squamous cell carcinoma is relatively rare in North America, the current study from Memorial Sloan Kettering Cancer Center is by no means easy. In terms of surgical procedure issues, which is contentious among Asian surgeons, my question is how to interpret the effect of various dissection or anastomotic techniques on the outcomes. Thank you!

Dr Molena. Most of our patients underwent Ivor Lewis esophagectomy (62\%). We always check margins intraoperatively to make sure there is no residual disease on the esophagus. We didn't notice any difference among the groups that had a 3-hole esophagectomy versus an Ivor Lewis esophagectomy in our series.

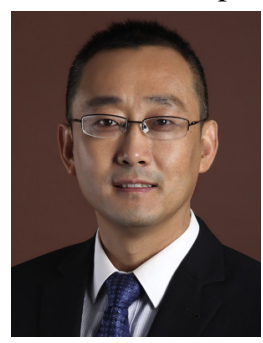

Dr Haoxian Yang (Guangzhou, China). Congratulations for the important work and great presentation. I am also from China and Sun Yat-sen University Cancer Center. I think this is very important, especially in the Asian countries, because most of the patients in Asian countries have squamous cell carcinoma, such as China.

I have 2 questions. First, how many patients achieved a pathologic CR in the trimodality group, and the second is, what about the time for surgery after induction therapy?

Dr Molena. We had a 47\% rate of PCR in the group of patients who underwent trimodality surgery, and the delay from the end of therapy to surgery was a median of 2 months.

Dr Moon. Any final comments, Dr Sugarbaker?

Dr Sugarbaker. Yes. I would like to say that this excellent retrospective study I think will hopefully lay the groundwork for a prospective phase II trial, possibly multi-institutional, where we could standardize the infusion phase for squamous cell carcinoma treatment in terms of radiation chemotherapy with an intent-to-treat design. I think we might be able to make significant progress on the basis of this study. Thank you. 
491 Patients with esophageal SCC

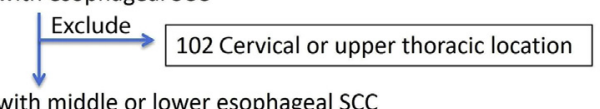

389 Patients with middle or lower esophageal SCC

356 Patients with cStage II or III middle or lower esophageal SCC
\[ \begin{array}{l}58 \text { Surgery only } \\ \text { Exclude }\end{array} \]
$\begin{array}{ll}\text { 22 No concurrent treatment } \\ 6 \text { History of previous esophageal cancer } \\ 3 \text { No treatment } \\ 3 \text { Emergent surgery (perforation or fistula) } \\ 8 \text { No treatment information }\end{array}$

256 Patients with cStage II or III middle or lower esophageal SCC,

treated with concurrent chemotherapy and radiation

232 Patients with cStage II or III middle or lower esophageal SCC,

treated with concurrent chemotherapy and radiation

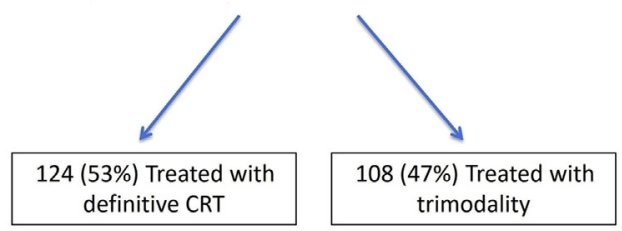

FIGURE E1. Consolidated Standards of Reporting Trials flow diagram showing selection of patients included in the current study, on the basis of inclusion and exclusion criteria. SCC, Squamous cell carcinoma; cStage, clinical stage; $C R T$, chemoradiotherapy; trimodality, neoadjuvant chemoradiotherapy followed by surgery. 
TABLE E1. Overview of surgical patients: Definitive chemoradiotherapy followed by salvage surgery versus trimodality

\begin{tabular}{|c|c|c|c|}
\hline Characteristic & Definitive CRT and salvage surgery $(n=17)$ & Trimodality $(\mathrm{n}=\mathbf{1 0 8})$ & $\boldsymbol{P}$ \\
\hline $\begin{array}{l}\text { Age, y } \\
\text { Median (IQR) } \\
\text { Range }\end{array}$ & $\begin{array}{c}67(57-73) \\
47-78\end{array}$ & $\begin{array}{c}60(56-67) \\
21-78\end{array}$ & .06 \\
\hline $\begin{array}{l}\text { Sex } \\
\text { Female } \\
\text { Male }\end{array}$ & $\begin{array}{r}5(29) \\
12(71)\end{array}$ & $\begin{array}{l}50(46) \\
58(54)\end{array}$ & .29 \\
\hline $\begin{array}{l}\text { Race } \\
\text { Caucasian } \\
\text { Asian } \\
\text { African American } \\
\text { Hispanic } \\
\text { NA }\end{array}$ & $\begin{array}{l}13(76) \\
1(6) \\
2(12) \\
1(6) \\
\quad 0\end{array}$ & $\begin{array}{r}81(78) \\
12(12) \\
8(8) \\
3(3) \\
4\end{array}$ & .63 \\
\hline $\begin{array}{l}\text { Tumor location } \\
\text { Middle } \\
\text { Distal }\end{array}$ & $\begin{array}{r}6(35) \\
11(65)\end{array}$ & $\begin{array}{l}46(43) \\
62(57)\end{array}$ & .61 \\
\hline $\begin{array}{l}\text { Differentiation* } \\
\text { Well/moderate } \\
\text { Poor }\end{array}$ & $\begin{array}{r}13(76) \\
4(24)\end{array}$ & $\begin{array}{l}67(67) \\
33(33)\end{array}$ & .58 \\
\hline $\begin{array}{l}\text { Radiation dose, cGy } \\
\quad \leq 5040 \\
\geq 5040\end{array}$ & $\begin{array}{r}13(76) \\
4(24)\end{array}$ & $\begin{array}{l}96(89) \\
12(11)\end{array}$ & .23 \\
\hline $\begin{array}{l}\text { Chemotherapy duration, mo } \\
\text { Median (IQR) } \\
\text { Range }\end{array}$ & $\begin{array}{c}2.4(2.2-2.8) \\
0-14.9\end{array}$ & $\begin{array}{c}2.1(1.3-2.5) \\
0.2-4\end{array}$ & .04 \\
\hline $\begin{array}{l}\mathrm{SUV}_{\max } \text { post-treatment } \\
\text { Median (IQR) } \\
\text { Range }\end{array}$ & $\begin{array}{c}2.6(1-5.8) \\
0-8.9\end{array}$ & $\begin{array}{c}3.5(0.5-5.3) \\
0-19.4\end{array}$ & .66 \\
\hline Median end of radiotherapy to surgery (IQR), mo & $8.7(5.3-10.7)$ & $2(1.6-2.9)$ & $<.0001$ \\
\hline 30-d postoperative mortality & $3(18)$ & $2(2)$ & .02 \\
\hline $\begin{array}{l}\text { Surgery type }(\mathrm{n}=15 \text { and } 105) \\
\text { Ivor Lewis } \\
\text { 3-hole } \\
\text { Other }\end{array}$ & $\begin{array}{l}7(47) \\
7(47) \\
1(6)\end{array}$ & $\begin{array}{c}67(64) \\
35(33) \\
3(3)\end{array}$ & .028 \\
\hline Respiratory complication grade $\geq 3$ & $5(29)$ & $12(11)$ & .06 \\
\hline Cardiac complication grade $\geq 3$ & 0 & $1(1)$ & 1 \\
\hline Anastomotic leak grade $\geq 3$ & $3(18)$ & $6(6)$ & .11 \\
\hline Other complication grade $\geq 3$ & $1(6)$ & $10(9)$ & .99 \\
\hline $\begin{array}{l}\text { Pathological stage } \\
0 \\
\text { I } \\
\text { II } \\
\text { III } \\
\text { NA }\end{array}$ & $\begin{array}{r}1(7) \\
3(20) \\
8(53) \\
3(20) \\
2 \dagger\end{array}$ & $\begin{array}{c}49(47) \\
8(8) \\
29(28) \\
19(18) \\
3 \ddagger\end{array}$ & .006 \\
\hline
\end{tabular}

Unless otherwise noted, data are no. (\%).CRT, Chemoradiotherapy; trimodality, neoadjuvant chemoradiotherapy followed by surgery; IQR, interquartile range; $N A$, not available; $S U V_{\max }$, maximum standardized uptake value. *Unknown for 16 patients prematching. $\dagger$ Two patients with local recurrence had unresectable disease (12\%). $\ddagger$ Two patients had unresectable disease (2\%), and 1 patient had surgery at an outside hospital $(1 \%)$. 
TABLE E2. Models of overall survival: Treatment, year of treatment, and unbalanced covariates

\begin{tabular}{lccc}
\hline \multicolumn{1}{c}{ Variable } & HR & $\mathbf{9 5} \% \mathbf{C I}$ & $\boldsymbol{P}$ \\
\hline Model 1 & & & \\
$\quad$ Treatment, trimodality vs CRT & 0.58 & $0.34-0.98$ & .044 \\
$\quad$ Treatment after 2009, yes vs no & 0.63 & $0.36-1.11$ & .107 \\
$\quad$ Chemotherapy duration, per month & 0.92 & $0.67-1.27$ & .626 \\
Model 2 & & & \\
$\quad$ Treatment, trimodality vs CRT & 0.60 & $0.35-1.02$ & .06 \\
$\quad$ Treatment after 2009, yes vs no & 0.59 & $0.33-1.04$ & .066 \\
$\quad$ Diabetes, yes vs no & 1.79 & $0.86-3.72$ & .121 \\
Model 3 & & & \\
$\quad$ Treatment, trimodality vs CRT & 0.57 & $0.33-0.97$ & .038 \\
$\quad$ Treatment after 2009, yes vs no & 0.63 & $0.36-1.12$ & .116 \\
$\quad$ Previous chest radiation, yes vs no & 1.97 & $0.47-8.26$ & .354 \\
\hline
\end{tabular}

HR, Hazard ratio; $C I$, confidence interval; trimodality, neoadjuvant chemoradiotherapy followed by surgery; $C R T$, chemoradiotherapy.
TABLE E3. Models of disease-free survival: Treatment, year of treatment, and unbalanced covariates

\begin{tabular}{llll}
\hline \multicolumn{1}{c}{ Variable } & HR & $\mathbf{9 5} \%$ CI & $\boldsymbol{P}$ \\
\hline $\begin{array}{l}\text { Model 1 } \\
\quad \text { Treatment, trimodality vs CRT }\end{array}$ & 0.52 & $0.32-0.85$ & .009 \\
$\quad$ Treatment after 2009, yes vs no & 0.71 & $0.43-1.16$ & .171 \\
$\quad$ Chemotherapy duration, per month & 0.9 & $0.68-1.19$ & .458 \\
Model 2 & & & \\
$\quad$ Treatment, trimodality vs CRT & 0.53 & $0.32-0.86$ & .01 \\
$\quad$ Treatment after 2009, yes vs no & 0.67 & $0.41-1.1$ & .115 \\
$\quad$ Diabetes, yes vs no & 1.32 & $0.68-2.56$ & .409 \\
Model 3 & & & \\
$\quad \begin{array}{l}\text { Treatment, trimodality vs CRT } \\
\quad \text { Treatment after 2009, yes vs no }\end{array}$ & 0.51 & $0.31-0.82$ & .006 \\
$\quad$ Previous chest radiation, yes vs no & 1.9 & $0.43-1.15$ & .161 \\
\hline HR, Hazard ratio; $C I$, confidence interval; trimodality, neoadjuvant chemoradiother- \\
apy followed by surgery; $C R T$, chemoradiotherapy.
\end{tabular}

